\title{
Insecticidal and growth regulatory effect of Jatropha curcas and Linum usitatissimum extracts along with new chemistry pesticide spinetoram against Sargodha strain of Rhyzopertha Dominica
} \author{
Taimur ${ }^{2}$ and Rabia Shabir ${ }^{4}$ \\ ${ }^{1}$ Department of Zoology (wildlife and fisheries), University of Agriculture Faisalabad. \\ 2 Department of Entomology, University of agriculture Faisalabad. \\ ${ }^{3}$ Department of Plant Pathology, University of agriculture Faisalabad \\ ${ }^{4}$ Institute of Pure and Applied Biology, B.Z.U Multan
}

Bushra Moon 1, ${ }^{*}$, Mahwish Razzaq 1, Muhammad Haseeb 3, Sania Iftikhar 1, Marriyam Mushtaq 1, Muhammad

GSC Biological and Pharmaceutical Sciences, 2021, 17(03), 137-143

Publication history: Received on 11 November 2021; revised on 13 December 2021; accepted on 15 December 2021

Article DOI: https://doi.org/10.30574/gscbps.2021.17.3.0359

\begin{abstract}
Store grain insect pests such as Lesser grain borer (Rhyzopertha dominica) is a key feeder and cause substantial weight loss of wheat during storage. Present study was planned to evaluate insecticidal, repellent and growth regulator potential of botanical extracts of two plants Jatropha curcas and Linum usitatissimum along with Spinetoram against Rhyzopertha Dominica. This study was conducted at the Department of Entomology, University of Agriculture, Faisalabad (UAF) Grain Research, Training, and Storage Management Cell. Each treatment with three replication of 5\%, $10 \%$, and $15 \%$ concentrations of plant extracts and $100 \mathrm{ppm}, 200 \mathrm{ppm}$, and $300 \mathrm{ppm}$ concentrations of insecticide were used against the adults of $R$. dominica by using Complete Randomized Design. Insect mortality was taken after 24,48 , and 72 hours after treatment. Data of growth regulation data was observed after 30 and 60 days. Data was analyzed by statistic 8.1 software for analysis of variance at $5 \%$ level of significance and treatment means was compared with the help of Tukey's Honestly Significant Difference (THSD) test. After 72 hours, Spinetoram showed maximum percent mortality (84\%) followed by J. curcas $(19.17 \%)$ and L. usitatissimum $(12.28 \%)$ at their higher concentrations rate. Among treatments, after 60 days of exposure, Spinetoram was proved to be more effective against the $R$. dominica with maximum growth inhibition (70\%) as compared to J. curcas (44\%) and Linseed (28\%). Overall the results indicated that these plant extracts and Spinetoram can be used as efficient alternatives of synthetic chemicals for management of stored grains insect pests.
\end{abstract}

Keywords: Mortality; Plant extract; Growth inhibition; Efficacy; Stored grain

\section{Introduction}

Stored grain insects are the most destructive and damaging pests which are very difficult to control because of their unusual feeding habits, small size and the ability to attack grains before harvest (Raghavendra et al., 2017). Among stored grain insect pests, lesser grain borer, Rhyzopertha dominica (Bostrichidae; Coleoptera) is a crucial pest which have the ability to infest unbroken grains and attack different cereal crops (Edde et al., 2012). R. dominica along with other stored insect pests can cause numerous economic losses to agriculture commodities (Arthur et al., 2012). It is a cosmopolitan species found all around the world, infest during harvesting period and also in godwns, granaries, and other storage structures (Nadeem et al., 2011). R. dominica is believed to be originated as a wood borer from the tropical region of Indian subcontinent and expanding its host range to small grains (Jia et al., 2008).

\footnotetext{
* Corresponding author: Bushra Moon; E-mail:Bushra555zafar@gmail.com

Department of Zoology (wildlife and fisheries), University of Agriculture Faisalabad, Pakistan. 
In almost all the countries, the stored product insects are control by synthetic chemicals either in form of fumigants or insecticides (Rehman et al., 2019). These insecticides are widely used because of their effectiveness, effortless execution and easy storage properties (Darwish et al., 2013).Due to inappropriate and frequent use of pesticides causing adverse toxic effects for human beings and for natural fauna and flora (Benhalima et al., 2004). Therefore, lethal and injurious consequences of synthetic chemicals has necessitated the consideration of alternative methods like bio-insecticides derived from plant material are eco-friendly and are safe for harmonious fortification of man and the surroundings (Kavallieratos et al., 2005; Vassilakos et al., 2012; Islam et al., 2017).

Spinosyns group is a best example of commercial development of using natural products in a novel way to find valuable new products (Kirst et al., 2010). It can be used for organophosphorous and pyrethroid resistance strains of several stored grain pests and more effective against the $R$. dominica than the other grain protectants (Daglish et al., 2008).

Plant extracts are also considered one of the alternative methods to synthetic chemicals for insect pest management. Botanical insecticides are mostly used as extracts, oils or powders and they have a variety of ins ecticidal and antifeedent properties (Jaleel et al., 2015). Jatropha curcas (Euphorbiaceae, Malpighiales) also known as 'diesel plant' is a widely available tropical plant and often used for fencing by farmers (Jide-Ojo et al., 2013). This plant has been used for a very long time for the medicinal and veterinary purpose. Root and seed parts of plant have various cytotoxic, insecticidal, and nematicidal properties (Ahuchaogu and Ojiako et al., 2015). Its seeds oil has been mostly used as a biofuel and has a potential of toxicity therefore also used as a biopesticide (Jide-Ojo et al., 2013).

Linum usitatissimum (Linaceae, Malpighiales) commonly known as flaxseed or linseed, belongs to family. Flaxseed contains different phytochemicals such as triterpenoids, steroids, glycosides, saponins, alkaloids, flavonoids, tannins, carbohydrate and vitamin C (Yasmeen et al., 2018). Linseed oil has been used for centuries for industrial purpose. Its raw oil also used as astringent in fungicidal lotions, has moderate insect repellent properties and used as insecticide (Kaithwas et al., 2011).

Keeping in view the detrimental abilities of $R$. dominica, potential and eco-friendly properties of medicinal plants, this study was conducted under laboratory condition to examine the efficacy of the some plant extracts along with actively improved insecticide against lesser grain borer. The objective of study is to investigate the growth regulatory effects of plant extracts (Jatropha and Linseed seeds) and insecticide (Spinetoram) against the population of Rhyzopertha dominica (F.).

\section{Material and methods}

\subsection{Collection and mass rearing of the bioassay insects}

Adults of Rhyzopertha dominica were collected from different grains handlings and storage localities (grain markets) of district Sargodha, Punjab Pakistan. These insects were brought back for mass reared in the laboratory to get homogenous insect culture of the test insect pest. Sterilized plastic jars (having 500gm Sterilized wheat) were used for mass rearing insect culture. To confined (avoid the escape) the population of the tested insect, plastic jars were covered with muslin cloth, tightened with rubber bands. The insects were reared on wheat grains flour (as diet). Counted number of adults (50 pairs) was released in the plastic jars and place under optimal growth conditions $\left(27+2{ }^{\circ} \mathrm{C}\right.$ and $65+5 \%$ R.H) of the insect. After 3 days, the released beetles were shifted to other jars. The sieved flour containing eggs was again placed into the plastic jars for rearing of the insect till achievement of same age adults, to be used for bioassays.

\subsection{Collection of plants parts for oil extraction}

Fresh seeds of Jatropha curcas were gathered from different location of UAF and Linum usitatissimum (Alsi) were purchased from the market of Sargodha. The seeds were washing by fresh water and shade dried in the laboratory. Then ground into powders with the help of electrical grinder. Plant oils were extracted against acetone in Soxhlet apparatus in 1:3 ratios of each plant powder (g) and acetone (dipping 50 gram of plant powder in 150 ml acetone). Extracted oils of the selected plants were poured into small cleaned reagent bottles, air tightened and then stored in refrigerator at 4 ${ }^{\circ} \mathrm{C}$ for further experimentations. New chemistry insecticides were purchased from spray market, located in Faisalabad.

\subsection{Mortality Bioassays}

Different concentrations (5, 10 and $15 \%$ ) of each of the plant oil and 100ppm, 200ppm, 300ppm new chemistry insecticide were prepared in acetone and water then applied on filter papers respectively. 20 adults of $R$. dominica (from homogenous population) were bio-assayed. After treatments application, all the experimental units (petri-dish) were 
placed in cool incubators and data regarding mortality of the test insect pest were recorded after 24,48 , and " 72 hr" of the post treatment application. Corrected mortality was calculated by using Abbott's (1925) Formula:

$$
\text { Corrected \% mortality = Observed mortality }- \text { Control mortality *100/100 - Control mortality }
$$

\subsection{Growth Regulation of lesser grain borer}

For estimation of the effect of seed extracts and insecticide on lesser grain borer, the survivor lesser grain borers were released in plastic containers on the weighed sterilized wheat. The containers were put in a thermostat apparatus at constant temperature and moisture for 60 days. This experimental unit was prepared for the three replications for each of tested concentrations and for control treatments. The population build-up levels were recorded after 30 and 60 days respectively.

\subsection{Statistical Analysis}

Data was analyzed by using the statistic 8.1 software for ANOVA and mean comparison tests with the help of THSD test.

\section{Results}

\subsection{Mortality data of Rhyzopertha Dominica against Spinetoram}

Table 1 Mean values of percent mortality of $R$. Dominica at different concentrations of new chemistry insecticide Spinetoram after 24,48 and 72 hours

\begin{tabular}{|c|c|c|c|}
\hline \multirow{2}{*}{ Concentration (ppm) } & \multicolumn{3}{|c|}{ Mean mortality \pm SE } \\
\cline { 2 - 4 } & $24 \mathrm{hrs}$. & $48 \mathrm{hrs}$. & $72 \mathrm{hrs}$. \\
\hline 100 & $23.34 \pm 1.92 \mathrm{~b}$ & $43.86 \pm 1.73 \mathrm{~b}$ & $66.67 \pm 2.31 \mathrm{~b}$ \\
\hline 200 & $47.05 \pm 1.89 \mathrm{a}$ & $74.51 \pm 1.75 \mathrm{a}$ & $88.24 \pm 2.34 \mathrm{a}$ \\
\hline 300 & $60.78 \pm 1.94 \mathrm{a}$ & $84.32 \pm 1.70 \mathrm{a}$ & $98.03 \pm 2.27 \mathrm{a}$ \\
\hline
\end{tabular}

Table 1 showed that mean percent mortality of adult lesser grain borer was directly related with the increase concentrations of Spinetoram and had no significant difference between them. At 300ppm concentration, highest mean mortality of adult lesser grain borer was 60.78 recorded after 24 hours while at 100ppm concentration, least mean mortality of 23.34 of adult lesser grain borer was noted. Similarly at 300ppm concentration of Spinetoram, highest mean mortality of $R$. Dominica was 84.32 recorded while at $100 \mathrm{ppm}$ concentration, least mean mortality of 43.86 of adult lesser grain borer was recorded. After 72 hours the highest mean mortality with value of 98.03 was observed while least mortality of 66.67 was observed after 72 hours with the application of Spinetoram.

\subsection{Mortality data of Rhyzopertha Dominica against Jatropha curcas}

The mean mortality of R. Dominica was observed after 24, 48 and 72hours of treatment of extract of Jatropha curcas at three different concentrations (5\%, 10\%, and 15\%). The following results showed the significance and efficacy of all three concentration of Jatropha extracts against $R$. Dominica.

Table 2 showed that mean mortality of $R$. Dominica was directly related with increase of concentrations of extract of Jatropha but had no significant difference between them. At 15\% concentration, the highest mean mortality of adult lesser grain borer was 14.03 recorded while at $5 \%$ concentration least mean mortality of 3.51 of adult lesser grain borer was noted. Correspondingly at $15 \%$ concentration, the highest mean mortality of adult lesser grain borer was 21.05 recorded while at $5 \%$ concentration least mean mortality of 8.77 of adult lesser grain borer was noted. Similarly after 72 hours at $15 \%$ concentration, the highest mean mortality of adult lesser grain borer was 25.93 recorded while at $5 \%$ concentration least mean mortality of 14.03 of adult lesser grain borer was recorded. 
Table 2 Mean values of data concerning mean mortality of adults of lesser grain borer $(R$. dominica) at different concentrations of Jatropha (Jatropha curcas) after different time intervals

\begin{tabular}{|c|c|c|c|}
\hline \multirow{2}{*}{ Concentration (\%) } & \multicolumn{3}{|c|}{ Mean mortality \pm SE } \\
\cline { 2 - 4 } & $24 \mathrm{hrs}$. & $48 \mathrm{hrs}$. & $72 \mathrm{hrs}$. \\
\hline 5 & $3.51 \pm 0.82 \mathrm{~b}$ & $8.77 \pm 1.07 \mathrm{~b}$ & $14.03 \pm 1.21 \mathrm{~b}$ \\
\hline 10 & $11.67 \pm 0.864 \mathrm{a}$ & $14.03 \pm 1.10 \mathrm{ab}$ & $17.54 \pm 1.25 \mathrm{ab}$ \\
\hline 15 & $14.03 \pm 0.79 \mathrm{a}$ & $21.05 \pm 1.04 \mathrm{a}$ & $25.93 \pm 1.19 \mathrm{a}$ \\
\hline
\end{tabular}

\subsection{Mortality data of Rhyzopertha dominica against Linum usitatissimum}

The mean mortality of $R$. dominica was observed after 24 hours of treatment of extract of Linseed at three different concentrations (5\%, 10\%, and 15\%). The following results showed the significance and efficacy of all three concentration of Linseed extracts against $R$. dominica.

Table 3 Mean values of data concerning mortality of adults of lesser grain borer (R. dominica) after 24 hours at different concentrations of Linseed (Linum usitatissimum)

\begin{tabular}{|c|c|c|c|}
\hline \multirow{2}{*}{ Concentration (\%) } & \multicolumn{3}{|c|}{ Mean mortality \pm SE } \\
\cline { 2 - 4 } & 24 hrs. & $48 \mathrm{hrs}$. & $72 \mathrm{hrs}$. \\
\hline 5 & $1.75 \pm 0.67 \mathrm{~b}$ & $3.51 \pm 1.00 \mathrm{~b}$ & $7.02 \pm 0.83 \mathrm{~b}$ \\
\hline 10 & $5.17 \pm 0.70 \mathrm{ab}$ & $8.77 \pm 1.04 \mathrm{ab}$ & $12.28 \pm 0.94 \mathrm{ab}$ \\
\hline 15 & $8.77 \pm 0.62 \mathrm{a}$ & $15.44 \pm 0.98 \mathrm{a}$ & $17.54 \pm 0.79 \mathrm{a}$ \\
\hline
\end{tabular}

Table 3 showed that mean mortality of $R$. Dominica was directly related with increase of concentrations of extract of Linseed but had no significant difference between them. After 24 hours at $15 \%$ concentration, the highest mean mortality of adult $R$. dominica was 8.77 noted while at 5\% concentration least mean mortality of 1.75 of adult lesser grain borer was recorded. After 48 hours 15\% concentration, the highest mean mortality of adult of $R$. dominica was 15.44 recorded while at $5 \%$ concentration least mean mortality of 3.51 of adult lesser grain borer was noted. Linum usitatissimum at $15 \%$ concentration give highest mean mortality 17.54 of lesser grain borer while at $5 \%$ concentration least mean mortality of 7.02 of adult lesser grain borer was noted.

\subsection{Analysis of variance of Growth inhibition (GI) of Rhyzopertha dominica after 30 days against the different concentration of Spinetoram, Jatropha curcas and Linum usitatissimum}

The mean GI of $R$. dominica was observed after 30 and 60 days treatment of Spinetoram at three concentrations $(100 \mathrm{ppm}, 200 \mathrm{ppm}$, and $300 \mathrm{ppm})$. The following results indicated the potential of Spinetoram for controlling the population of $R$. dominica. Along this the mean GI of $R$. Dominica was observed after 30 days of treatment of seed extract of Jatropha at three concentrations (5\%,10\%, and 15\%). The following results showed the potential of Jatropha curcas (Jatropha) and Linum usitatissimum (Linseed) extract against $R$. Dominica at different concentrations.

Table 4 Mean value of data concerning growth inhibition of lesser grain borer (R. dominica) population after exposure to different concentrations of Spinetoram, Jatropha and Linseed after 30 and 60 days

\begin{tabular}{|l|l|l|l|l|l|l|l|}
\hline & \multicolumn{6}{|c|}{ Mean population inhibition \pm SE } \\
\hline \multirow{2}{*}{ C. (ppm) } & \multicolumn{2}{|c|}{ Spinetoram } & \multirow{2}{*}{ C. $(\%)$} & \multicolumn{2}{c|}{ Jatropha } & \multicolumn{3}{c|}{ Linseed } \\
\cline { 2 - 7 } & $\mathbf{3 0}$ days & $\mathbf{6 0}$ days & & $\mathbf{3 0}$ days & $\mathbf{6 0}$ days & $\mathbf{3 0}$ days & $\mathbf{6 0}$ days \\
\hline $\mathbf{1 0 0}$ & $41.11 \pm 1.28 \mathrm{~b}$ & $45.06 \pm 0.92 \mathrm{c}$ & $\mathbf{5}$ & $27.380 \pm 1.33 \mathrm{~b}$ & $37.210 \pm 0.64 \mathrm{~b}$ & $15.56 \pm 1.03 \mathrm{~b}$ & $28.70 \pm 0.87 \mathrm{a}$ \\
\hline $\mathbf{2 0 0}$ & $46.43 \pm 1.32 \mathrm{~b}$ & $57.14 \pm 1.20 \mathrm{~b}$ & $\mathbf{1 0}$ & $37.503 \pm 1.45 \mathrm{~b}$ & $42.857 \pm 0.43 \mathrm{~b}$ & $24.34 \pm 1.20 \mathrm{~b}$ & $44.14 \pm 0.59 \mathrm{~b}$ \\
\hline $\mathbf{3 0 0}$ & $67.78 \pm 1.26 \mathrm{a}$ & $70.37 \pm 0.83 \mathrm{a}$ & $\mathbf{1 5}$ & $48.717 \pm 1.34 \mathrm{a}$ & $52.360 \pm 0.86 \mathrm{a}$ & $46.21 \pm 1.10 \mathrm{a}$ & $57.52 \pm 0.86 \mathrm{c}$ \\
\hline
\end{tabular}


Table 4 showed that mean growth inhibition in lesser grain borer was directly related with the increase concentrations of Spinetoram, as with the increase of concentration progeny production decreases. At 300ppm concentration, the highest mean growth inhibition in lesser grain borer population was 67.783 noted while at 100 ppm concentration least mean growth inhibition in $R$. dominica was 41.113 recorded after 30 days. Whereas After 60 days at 300 ppm concentration, the highest mean growth inhibition in lesser grain borer population was 70.370 recorded and the least mean growth inhibition in $R$. dominica was 45.060 at $100 \mathrm{ppm}$ concentration.

The mean growth inhibition in $R$. dominica was also directly related with the increase concentrations of Jatropha, as with the increase of concentration progeny production decreases. At 15\% concentration, the highest mean growth inhibition in lesser grain borer population was 48.717 and 52.360 recorded while at 5\% concentration least mean growth inhibition in $R$. dominica was 27.380 and 37.210 recorded after 30 and 60 days respectively. Linseed concentration at $15 \%$, the highest mean growth inhibition in $R$. dominica population was 46.21 after 30 days and 57.52 after 60 days while at 5\% concentration least mean growth inhibition in $R$. dominica was 15.56 and 28.70 after 30 and 60 days respectively.

\section{Discussion}

The present study has been carried to evaluate the appropriate concentration for botanical extracts (Jatropha curcas and Linum usitatissimum) and insecticide (Spinetoram) against $R$. dominica to find out some safe alternatives of noxious chemical for the control of notorious stored grain insect pests. The results revealed that the exposure period and concentrations of tested plant extracts and tested insecticide against $R$. dominica varied greatly in terms of mortality, repellency and growth inhibitory factors.

Higher \% mortality by Spinetoram was close to Vassilakos et al. $(2012 ; 2015)$ who found the same results as in the present study with the application of Spinetoram against the adults of $R$. dominica. Whereas, the least toxicity of linseed was confirmed by Islam et al. (2017) who assessed the toxicity of linseed with extracts of Indian fumitory and English violet against $T$. castaenum. In present study, the extracts of Jatropha curcas gave mortality value of $19.17 \%$ at higher concentration (15\%) after 72 hours is close to Ojiako et al. (2014) and Usman et al. (2019) who used Jatropha curcas against stored grain insect pests and recorded higher mortality of insect pests.

Maximum growth inhibition (\%) of $R$. dominica was recorded by Spinetoram than tested plant extracts. At highest concentration $(300 \mathrm{ppm})$, about $67.78 \%$ and $70.37 \%$ growth inhibition against R. dominica was obtained after 30 and 60 days, respectively. And about 41\% and 45\% growth inhibition (\%) with slight difference was observed at low concentration (100ppm) of Spinetoram after 30 and 60 days, respectively. Similar growth inhibitory effect of Spinetoram against stored grain insect pests was also recorded by Vassilakos et al. (2012); Salgam et al (2013); Vassilakos et al. (2015) and Rumbos et al. (2018).

In present study, about $48.71 \%$ and $52.36 \%$ growth inhibition by Jatropha extract along with $46.21 \%$ and $57.52 \%$ by linseed was recorded against $R$. dominica at highest concentration (15\%) after 30 and 60 days, respectively. While in past Namdev et al. (2014) and Islam et al. (2017) also recorded the effectiveness of linseed in case of progeny inhibition and observed less effective results than other tested plant extracts. Application of Jatropha and linseed may significantly inhibit the progeny production of $R$. dominica for long time period as proved by present study.

\section{Conclusion}

The mortality was increased by increasing the concentration of spinetoram and exposure time. Increased repellency was found at increased concentrations of plants extracts. Therefore, it is suggested that Linseed (15\%), Jatropha (15\%) and Spinetoram $(300 \mathrm{ppm})$ at higher concentration along with longer exposure periods can be an effective alternative to synthetic chemicals for eco-friendly management of stored commodity by insect pests.

\section{Compliance with ethical standards}

\section{Acknowledgments}

Acknowledged for all the authors they contribute equally in this research work. 


\section{Disclosure of conflict of interest}

No conflict of interest.

\section{References}

[1] Abbot WS. A method of computing the effectiveness of an insecticide. J. econ. Entmol. 1925; 18: 265-267.

[2] Ahuchaogu CE, FO Ojiako. Comparative study of the toxic effects of Jatropha curcas L. extracts and Actellic 25 EC $\left({ }^{8}\right.$ on Callosobruchus maculatus (FABRICIUS) (Coleoptera: Chrysomelidae: Bruchinae) in stored cowpea. FUTA. J. Res. Sci. 2015; 2: 231-242.

[3] Arthur F, G Ondier, T Siebenmorgen. Impact of Rhyzopertha dominica (F.) on quality parameters of milled rice. J. Stored Prod. Res. 2012; 48: 137-142.

[4] Benhalima H, MQ Chaudhry, KA Mills, NR Price. Phosphine resistance in stored-product insects collected from various grain storage facilities in Morocco. J. Stored Prod. Res. 2004; 40: 241-249.

[5] Daglish GJ, MK Nayak. Long-term persistence and efficacy of Spinosad against Rhyzopertha dominica (Coleoptera: Bostrychidae) in wheat. Pest Manag. Sci. 2006; 62: 148-152.

[6] Darwish YA, YM Omar, RE Hassan, MA Mahmoud. Repellent effects of certain plant essential oil, plant extracts and inorganic salts to granary weevil, Sitophilus granarius (L.). Arch. Phytopathology. Plant Prot. 2013; 46: 19491957.

[7] Edde PA. A review of the biology and control of Rhyzopertha dominica (F.) the lesser grain borer. J. Stored Prod. Res. 2012; 48: 1-18.

[8] Islam W, A Rasool, Z Wu. Inhibitory effects of medicinal plant extracts against Tribolium castaneum (Herbst.) (Coleoptera: Tenebrionidae). J. Agri. Sci. 2017; 3: 15-20.

[9] Islam W, A Rasool, Z Wu. Inhibitory effects of medicinal plant extracts against Tribolium castaneum (Herbst.) (Coleoptera: Tenebrionidae). J. Agri. Sci. 2017; 3: 15-20.

[10] Jaleel W, Q Saeed, S Saeed, T Ansari, MN Naqqash, N Iqbal, U Sial. Efficacy and time mortality of Tribolium castaneum (Herbst) (Coleoptera: Tenebrionidae) by some essential oils through contact and fumigant methods. Appl. Sci. Bus. Econ. 2015; 2: 1-7.

[11] Jia F, MD Toews, JF Campbell, SB Ramaswamy. Survival and reproduction of lesser grain borer, Rhyzopertha dominica (F.)(Coleoptera: Bostrichidae) on flora associated with native habitats in Kansas. J. Stored Prod. Res. 2008; 44: 366-372.

[12] Jide-Ojo C, DT Gungula, 00 Ojo. Extracts of Jatropha curcas L. exhibit significant insecticidal and grain protectant effects against maize weevil, Sitophilus zeamais (Coleoptera: Curculionidae). J. Stored Prod. Postharvest Res. 2013; 4: 44-50.

[13] Kaithwas G, A Mukerjee, P Kumar, DK Majumdar. Linum usitatissimum (linseed/flaxseed) fixed oil: antimicrobial activity and efficacy in bovine mastitis. Inflammopharmacol. 2011; 19: 45-52.

[14] Kavallieratos NG, CG Athanassiou, FG Pashalidou, NS Andris, Ž Tomanović. Influence of grain type on the insecticidal efficacy of two diatomaceous earth formulations against Rhyzopertha dominica (F) (Coleoptera: Bostrychidae). Pest Manag. Sci. 2005; 61: 660-666.

[15] Kirst HA. The spinosyn family of insecticides: realizing the potential of natural products research. J. Antibiot. 2010; 63: 101-111.

[16] Nadeem S, M Hamed, M Shafique. Feeding preference and developmental period of some storage insect species in rice products. Pak. J. Zool. 2011; 43: 79-83.

[17] Namdev HP, RS Singh, MK Anuragi. Efficacy of indigenous oils on growth and development of Callosobruchus chinensis infesting Black gram. Ann. Plant Prot. Sci. 2014; 22: 283-286.

[18] Ojiako FO, SA Dialoke, GO Ihejirika, CE Ahuchaogu, HI Iheaturueme. Management of stored maize against Sitophilus zeamais Motschulsky (Coleoptera: Curculionidae) with the seed and root powders of Jatropha curcas (L.). Int. J. Agric. Rur. Dev. 2014; 17: 1899-1904. 
[19] Raghavendra D, T Manoharan, G Preeta. Evaluation of Plant Oils as Synergists in Suppression of Malathion Resistance in Sitophilus oryzae (L.) and Tribolium castaneum (Herbst.). Int. J. Curr. Microbiol. Appl. Sci. 2017; 6: 909-917.

[20] Rehman H, A Qurban, S Mirza, S Sharif, M Hasan, M Yasir. Comparative toxic potential of some plant extracts and Spinetoram against Tribolium castaneum (Herbst, 1797) (Coleoptera: Tenebrionidae). Türk. Entomol. Derg. 2019; 43: 201-210.

[21] Rumbos CI, AC Dutton, CG Athanassiou. Insecticidal effect of Spinetoram and thiamethoxam applied alone or in combination for the control of major stored-product beetle species. J. Stored Prod. Res. 2018; 75: 56-63.

[22] Saglam O, CG Athanassiou, TN Vassilakos. Comparison of Spinetoram, imidacloprid, thiamethoxam and chlorantraniliprole against life stages of Tribolium confusum Jacquelin du Val (Coleoptera: Tenebrionidae) on concrete. Crop Prot. 2013; 53: 85-95.

[23] Usman M, Q Majeed, K Abdullahi, M Sokoto, H Mainasara. Toxicity of some plant powders to lesser grain borer (Rhyzopertha dominica (fab.); Coleoptera: Bostrichidea) infesting stored sorghum. Int. J. Adv. Acad. Res. Sci. Technol. Engr. 2009; 5: 73-81.

[24] Vassilakos TN, CG Athanassiou. Effect of short exposures to Spinetoram against three stored-product beetle species. J. Econ. Entomol. 2012; 105: 1088-1094.

[25] Vassilakos TN, CG Athanassiou, NG Tsiropoulos. Influence of grain type on the efficacy of Spinetoram for the control of Rhyzopertha dominica, Sitophilus granarius and Sitophilus oryzae. J. Stored Prod. Res. 2015; 64: 1-7.

[26] Yasmeen M, S Nisar, V Tavallali, T Khalid. A review of phytochemicals and uses of flaxseed. Int. J. Chem. Biochem. Sci. 2018; 13: 70-75. 